Check for updates

Cite this: RSC Adv., 2019, 9, 16790

Received 13th April 2019

Accepted 22nd May 2019

DOI: 10.1039/c9ra02787d

rsc.li/rsc-advances

\section{Ultrafast synthesis of AFX-Type zeolite with enhanced activity in the selective catalytic reduction of NOx and hydrothermal stability $\dagger$}

\author{
Anand Chokkalingam, ${ }^{a}$ Watcharop Chaikittisilp, (D) $t^{a}$ Kenta lyoki, (D) a Sye Hoe Keoh, ${ }^{a}$

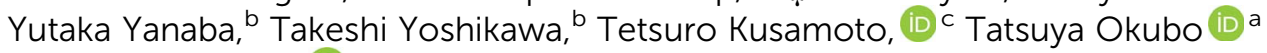 \\ and Toru Wakihara (D) *a
}

\begin{abstract}
Shortening the synthesis time of SSZ-16 (AFX type) zeolite from several days to $2 \mathrm{~h}$ has been achieved using an ultrafast synthesis route involving $N, N, N^{\prime}, N^{\prime}$-tetraethylbicyclo[2.2.2]oct-7-ene-2,3:5,6-dipyrrolidinium (TEBOP) as an organic structure-directing agent (OSDA) in a tubular reactor assisted by seed crystals. Recently, copper exchanged SSZ-16 has been looked upon as one of the few equivalents to SSZ-13 for the selective catalytic reduction of $\mathrm{NOx}$ with ammonia ( $\mathrm{NH}_{3}-\mathrm{SCR}$ ) from automobile exhausts. Hydrothermal stability is one of the crucial properties for any zeolites that compete for automobile applications. All the samples prepared were analyzed using sophisticated physio-chemical techniques and those prepared from TEBOP were subjected to SCR of NOx reactions. The rapid crystal growth induced by high synthesis temperature bestowed the ultrafast prepared SSZ-16 with high crystallinity and hydrothermal stability as well as enhanced SCR of NOx activity even when aged at $800^{\circ} \mathrm{C}$. Compared to 1,1'-(1,4-butanediyl)bis-4-aza-1-azoniabicyclo[2.2.2]octane dibromide (DABCO), TEBOP was found to be desirable as an OSDA for high crystallinity and hydrothermal stability.
\end{abstract}

\section{Introduction}

Zeolites have been studied as an alternative for the traditional mixed oxide catalysts based on vanadia for treating nitrogen oxides (NOx) emitted from combustion of fossil fuels. NOx is one of the prominent ingredients polluting global air quality and affecting human health for decades. Selective catalytic reduction of NOx with ammonia $\left(\mathrm{NH}_{3}\right.$-SCR) using on-board converters is recognized as one of the most advanced emission control technologies in meeting the emission standards set by environmental policies. ${ }^{\mathbf{1 - 1 0}}$ During the primordial infusion of the SCR technology for the conventional treatment of industrial emissions, mixed oxides of vanadium, tungsten and titanium were used as catalysts. However, their efficiency is limited to a narrow temperature window (i.e. $300-400{ }^{\circ} \mathrm{C}$ ), above which they volatilize and also succumb to toxins from secondary

\footnotetext{
${ }^{a}$ Department of Chemical System Engineering, The University of Tokyo, Tokyo, 113-8656, Japan.E-mail: wakihara@chemsys.t.u-tokyo.ac.jp

${ }^{b}$ Institute of Industrial Science, The University of Tokyo, Tokyo, 153-8505, Japan 'Department of Chemistry, Graduate School of Science, The University of Tokyo, Bunkyo-ku, Tokyo 113-0033, Japan

$\dagger$ Electronic supplementary information (ESI) available. See DOI: 10.1039/c9ra02787d

\$ Present address: Research and Services Division of Materials Data and Integrated System (MaDIS), National Institute for Materials Science (NIMS), 1-2-1 Sengen, Tsukuba, Ibaraki 305-0047, Japan.
}

emissions. ${ }^{8-10}$ To be a better SCR catalyst, the material should possess high hydrothermal stability.

Since the pioneering work on the SCR activity of Cu-ZSM-5, ${ }^{\mathbf{1 1}}$ numerous zeolites have been studied and mostly found to be unstable at high operating temperatures or lacking lowtemperature SCR activity ${ }^{\mathbf{1 2 - 1 4}}$ until the discovery of Cu-SSZ-13, which exhibited high hydrothermal stability as well as lowtemperature activity. ${ }^{15-18}$ Despite its success in SCR market, the flaws related to cold start and high temperature exhaust conditions seem to affect the SCR activity and structural stability of Cu-SSZ-13 as well, which has aroused interest on small pore zeolites with inherent large cavities capable of retaining their structural integrity despites repeated exposure to severe hydrothermal conditions. ${ }^{10,15,19}$ Even, some of them (SSZ16, SSZ-39, STA-7 and SSZ-52) are considered alternatives to SSZ13, particularly, SSZ-16 (AFX topology, see Fig. S1 $\dagger$ ) made up of elongated larger aft cages $(0.55 \times 1.35 \mathrm{~nm})$ and smaller gme cages $(0.33 \times 0.74 \mathrm{~nm})$ has drawn interest due to its promising catalytic performances in SCR of NOx. ${ }^{20-25}$ Recently, the SSZ-16 has been projected as a remarkable $\mathrm{NH}_{3}$-SCR catalyst achieving $\sim 100 \%$ NOx conversion owing to ease of pore accessibility and generates research interests on developing its physicochemical aspects from an SCR performance perspective. ${ }^{\mathbf{2 6 , 2 7}}$ However, reports dedicated to reducing its synthesis time from an industrial view point (i.e. production cost) are scanty. For many years zeolites have been overlooked as potential applicants in number of industrial applications 
particularly because of the assumption that their syntheses are time elongated, and thus involve high production cost. This has led to innovative studies that report efficient methods to produce zeolites in short period of time. ${ }^{28-31}$

Temperature, a significant factor in zeolite syntheses that govern the rate of nucleation and crystal growth is crucial for shortening the synthesis time of zeolites, which would otherwise take several days to even weeks. Hitherto, the complexity surrounding the zeolite formation mechanism remains unexplained and many studies have suggested that in fact, it is the nucleation that consumes much time rather than the crystal growth. ${ }^{30-34}$ Recently, the ultrafast synthesis techniques that involves tubular reactor with the assistance of seed that reduces the synthesis time of zeo-type and zeolites viz., AFI, CHA, MFI, ERI, and MOR down to several minutes were reported by us. ${ }^{30,35-42}$ Table $\mathrm{S} 1 \dagger$ compares the experimental conditions of these zeolites with the current study. Tubular reactor has proven effective to overcome the thermal lag faced in conventional autoclave (Fig. $\mathrm{S} 2 \dagger$ ), which allows rapid heat transfer, capable of producing zeolites in the order of minute rendering the synthesis of zeolites high quantitative efficiency in terms of time, energy and cost.

So far, several flexible OSDAs have been employed for preparing SSZ-16, ${ }^{43-50}$ but recently, a bulky OSDA with a rigid structure named TEBOP, often involved in the synthesis of MSEtype zeolites, was introduced for the synthesis of SSZ-16.43,44 However, it required at least $24 \mathrm{~h}$ for preparing the SSZ-16 using TEBOP in an autoclave and achieving it at a faster pace remained challenging because the degree of synthesis freedom offered by such small pore zeolites are quite narrow. ${ }^{43,44}$ Extending the ultrafast synthesis approach, we were able to synthesize SSZ-16 (AFX-type) zeolite in 2 hours using sealed tubular reactor which would otherwise require several days. ${ }^{4-51}$ The SSZ-16 from TEBOP bettered their DABCO counterpart with physio-chemical traits that are promising for enhanced SCR of NOx and in particular they were bestowed with excellent hydrothermal stability. Especially, the SSZ-16 prepared in a tubular reactor endured under the harsh hydrothermal treatment conditions (i.e. $800{ }^{\circ} \mathrm{C} \times 5 \mathrm{~h}$ with continuous streaming of humid air with 10 volume $\% \mathrm{H}_{2} \mathrm{O}$ ) by retaining $\sim 70 \%$ of its crystallinity and exhibiting NOx conversion over $80 \%$.

\section{Experimental section}

\subsection{Synthesis of SSZ-16 with DABCO}

Based on a previous report, DABCO (for molecular structure see Fig. S3†) was prepared and used as OSDA for SSZ-16 synthesis. ${ }^{51}$ In a typical synthesis, a reactant with a molar composition of $30.0 \mathrm{SiO}_{2}-1.0 \mathrm{Al}_{2} \mathrm{O}_{3}-12.0 \mathrm{Na}_{2} \mathrm{O}-3.0 \mathrm{DABCO}-520 \mathrm{H}_{2} \mathrm{O}$ involving FAU type zeolite (HSZ-373HUA, Tosoh, $\mathrm{Si} / \mathrm{Al}=15, \mathrm{H}^{+}$type) as both $\mathrm{Si}$ and $\mathrm{Al}$ sources was prepared by applying centrifugal force in a mixer (THINKY MIXER ARE-310). Then, the reactant transferred to a conventional Teflon lined stainless steel autoclave (AC) was treated at $140{ }^{\circ} \mathrm{C}$ for 2 days using a rotary oven under $20 \mathrm{rpm}$. Prior to calcination at $550{ }^{\circ} \mathrm{C}$ for $10 \mathrm{~h}$, the products in the AC were recovered by centrifugation, washed thrice with de-ionized water and dried overnight at $80{ }^{\circ} \mathrm{C}$. The calcined SSZ-16 prepared from DABCO is designated as ACDABCO.

\subsection{Synthesis of SSZ-16 seed with Et6-Diquat-5}

The OSDA, $N, N^{\prime}$-bis-triethylpentanediyldiammonium (Et6diquat-5, for molecular structure see Fig. S3 $\dagger$ ) was prepared by slightly modifying the recipe from a previous report. ${ }^{52}$ In a typical SSZ-16 synthesis, a reactant with a molar composition of $\quad 30.0 \mathrm{SiO}_{2}-0.5 \mathrm{Al}_{2} \mathrm{O}_{3}-30.0 \mathrm{NaOH}-3.0 \mathrm{OSDA}-1200.0 \mathrm{H}_{2} \mathrm{O}$ involving fumed silica (Aerosil 200, Degussa) as Si source and $\mathrm{Al}\left(\mathrm{NO}_{3}\right)_{3} \cdot 9 \mathrm{H}_{2} \mathrm{O}$ (Wako, Japan) as $\mathrm{Al}$ source was prepared by stirring at $90{ }^{\circ} \mathrm{C}$ for $72 \mathrm{~h}$ under $500 \mathrm{rpm}$. Then, it was treated at $150^{\circ} \mathrm{C}$ for 6 days under $22 \mathrm{rpm}$ after contained in AC. The SSZ16 thus produced was used as a seed.

\subsection{Synthesis of SSZ-16 with TEBOP}

The $20 \mathrm{wt} \%$ solution of TEBOP (for molecular structure see Fig. S3†) was prepared by a slightly modified recipe reported elsewhere $^{43}$. In a typical SSZ-16 synthesis, a reactant with a molar composition of $1.0 \mathrm{SiO}_{2}-0.092 \mathrm{Al}_{2} \mathrm{O}_{3}-0.1 \mathrm{NaOH}-$ 0.1TEBOP- $20.0 \mathrm{H}_{2} \mathrm{O}$ involving FAU type zeolite (HSZ-350HUA, Tosoh, $\mathrm{SiO}_{2} / \mathrm{Al}_{2} \mathrm{O}_{3}=10, \mathrm{H}^{+}$type) as both $\mathrm{Si}$ and $\mathrm{Al}$ sources was prepared by stirring at room temperature for $2 \mathrm{~h}$ under $400 \mathrm{rpm}$. Ten minutes prior to the hydrothermal treatment, the seed $\left(10 \mathrm{wt} \%\right.$ w.r.t. $\mathrm{SiO}_{2}$ content) was added and dispersed well into this reactant mixture. The mixture was treated static at $160{ }^{\circ} \mathrm{C}$ for 4 days after contained in AC. The SSZ-16 thus produced is designated as AC-TEBOP.

\subsection{Faster synthesis of SSZ-16 with TEBOP}

The synthesis of SSZ-16 at a faster pace was achieved by modifying the molar composition of the reactant slightly $\left(1.0 \mathrm{SiO}_{2}-\right.$ $0.092 \mathrm{Al}_{2} \mathrm{O}_{3}-0.15 \mathrm{NaOH}-0.15 \mathrm{TEBOP}-30.0 \mathrm{H}_{2} \mathrm{O}$ ), replacing the AC with tubular reactors (TRs) and increasing the temperature from 160 to $210{ }^{\circ} \mathrm{C}$. Prior to the fast synthesis, TRs were packed with the reactant (up to $75 \%$ of its total volume), sealed tightly using stainless steel caps (Swagelok, 1/4 inch, SS-400-C, at both ends) and immersed within a preheated oil bath connected with temperature controller and sensors. After $2 \mathrm{~h}$, the TRs were quenched in a cold water bath followed by sample recovery. The material thus obtained is designated as TR-TEBOP.

The yield of the samples were calculated with respect to the amount of $\mathrm{SiO}_{2}$ added to the initial gel. After applying the same recovery and calcination treatment conditions similar to ACDABCO, all the samples (except seed) were ion-exchanged with $1 \mathrm{M}$ solution $\left(1 \mathrm{~g}\right.$ SSZ-16/40 mL) of $\mathrm{NH}_{4} \mathrm{NO}_{3}$ (Wako, Japan) at $80{ }^{\circ} \mathrm{C}$ for $4 \mathrm{~h}$. After subjected to the ion-exchange treatment twice, the samples were dried overnight at $80^{\circ} \mathrm{C}$.

\subsection{Copper ion-exchange}

The ammonia forms of the samples were subjected to copper ion-exchange by stirring with $0.08 \mathrm{M}$ solution $(1 \mathrm{~g}$ sample/50 $\mathrm{mL}$ ) of $\mathrm{Cu}\left(\mathrm{CH}_{3} \mathrm{COO}\right)_{2}$ (Wako, Japan) at $100{ }^{\circ} \mathrm{C}$ under $400 \mathrm{rpm}$ for $4 \mathrm{~h}$ (thrice). The samples were recovered by centrifugation, 
dried and applied as catalysts in the SCR of NOx reactions. All the copper exchanged samples are designated with a "Cu" prefixed to their actual name and are collectively termed as "fresh".

\subsection{Hydrothermal stability test}

The copper ion-exchanged samples $(\sim 0.5 \mathrm{~g})$ were packed within the mid zone of a quartz tube contained by quartz wool at the bottom. A controlled heating of the tube to desired temperatures (every $50{ }^{\circ} \mathrm{C}$ from 700 to $800{ }^{\circ} \mathrm{C}$ ) was performed at a rate of $10^{\circ} \mathrm{C} \mathrm{m^{-1 }}$ under a constant flow of dry air $\left(100 \mathrm{~cm}^{3} \mathrm{~min}^{-1}\right)$. Once the temperature attains the target, a stream of humid air with 10 vol\% $\mathrm{H}_{2} \mathrm{O}$ is passed continuously for $5 \mathrm{~h}$. Further, the samples treated under hydrothermal stability test will be termed as "aged" and designated with a number (respective to their hydrothermal aging temperature) suffixed to their actual name.

\subsection{Characterization}

Structural elucidation of the samples by powder X-ray diffraction technique (XRD) were collected on Rigaku Ultima IV diffractometers with $\mathrm{CuK} \alpha$ radiation $(\lambda=1.5406 \AA$, $V=40 \mathrm{kV}, I$ $=40 \mathrm{~mA}$ ) with $4^{\circ} \mathrm{min}^{-1}$ scan rate. The crystallinity of the samples after hydrothermal treatment (HT) was obtained by peak fitting technique (Igor software) that calculates and compares the areas under the XRD peaks between the $2 \theta$ values $15^{\circ}$ to $35^{\circ}$ obtained before and after HT. Nitrogen $\left(\mathrm{N}_{2}\right)$ adsorption-desorption measurements were performed in a Quantachrome Autosorb-iQ2 instrument at liquid $\mathrm{N}_{2}$ temperature. Prior to the measurements, the samples were outgassed at $350{ }^{\circ} \mathrm{C}$ for $6 \mathrm{~h}$ under vacuum. The surface areas of the samples were calculated using a multipoint BET (Brunauer-Emmett-Teller) method (with the recommended relative pressure range $0.05-$ 0.2 ) and their micropore volumes were assessed using $t$-plot method. Morphology and particle size data were obtained from a field emission scanning electron microscope (FE-SEM, JSM7000F JEOL, Japan).

A Thermo iCAP 6300 inductively coupled plasma-atomic emission spectrometer (ICP-AES) was used to analyze the elemental composition of the samples. Electron Spin Resonance (ESR) spectroscopic data of selective samples were obtained using JEOL-JES-FA200 spectrometer on the X-Band frequency at room temperature. The ESR signals were recorded in the field region of 160 to $460 \mathrm{mT}$ with a microwave power of 2 $\mathrm{mW}$, a modulation frequency of $100 \mathrm{kHz}$, a central field of 310 $\mathrm{mT}$ and a sweep time of $30 \mathrm{~s}$. Solid-state magic angle spinning (MAS) nuclear magnetic resonance (NMR) spectroscope measurements were conducted on a JNM-ECA 500 (JEOL) instrument. ${ }^{29} \mathrm{Si}$ MAS NMR spectra were recorded at $99.37 \mathrm{MHz}$ with a $\pi / 2$ pulse length of $5.0 \mu \mathrm{s}$, a recycle delay of $60 \mathrm{~s}$ and a spinning frequency of $10 \mathrm{kHz} .{ }^{27} \mathrm{Al}$ MAS NMR spectra were recorded on a JEOL ECA 800 (18.8 T) spectrometer using a Larmor frequency of $208.49 \mathrm{MHz}$. All the measurements involved a JEOL $3.2 \mathrm{~mm}$ MAS probe and ZrO2 rotor (spun at $20 \mathrm{kHz}$ ). To ensure full relaxation of the ${ }^{27} \mathrm{Al}$ spins, the spectra were obtained by collecting 256 scans with a pulse of $\leq 0.27 \mu$ s and its repetition time of $1 \mathrm{~s}$. The ${ }^{27} \mathrm{Al}$ chemical shifts were calibrated with a $1 \mathrm{M}$ aqueous solution of $\mathrm{Al}\left(\mathrm{NO}_{3}\right)_{3}$ as $0 \mathrm{ppm}$.

\subsection{SCR reactor system}

The selective catalytic reduction of NOx experiments with $\mathrm{NH}_{3}$ were performed in a quartz fixed bed reactor measuring $8 \mathrm{~mm}$ in height. The quartz reactor was stuffed (maximum packing limit was $6 \mathrm{~mm}$ ) with $20 \mathrm{mg}$ of catalyst together with $280 \mathrm{mg} \mathrm{SiC}$ (silicon carbide). A pre-treatment of the catalyst was done by passing a mixture of gases $\left(\mathrm{O}_{2}: 5 \%, \mathrm{H}_{2} \mathrm{O}: 3 \%\right.$ and $\mathrm{N}_{2}$ : $\left.92 \%\right)$ using a mass flow controller. The experiments were conducted at a temperature ranging from 150 to $600{ }^{\circ} \mathrm{C}$ using a mixture of NO: $300 \mathrm{ppm}$ and $\mathrm{NH}_{3}: 300 \mathrm{ppm}$ with a flow rate of 200 $\mathrm{cm}^{3} \min ^{-1}$ and GHSV is $50000 \mathrm{~h}^{-1}$. The conversion readings were obtained for every $50{ }^{\circ} \mathrm{C}$ rise and analyzed by a quadrupole mass spectrometer (Q-MS).

\section{Results and discussion}

The structure of all the samples (before and after ion-exchange with copper) were highly crystalline and matched well with pure AFX phase as determined by XRD patterns (Fig. S4†). The influence of reactant ratio and OSDA over the physicochemical properties of these samples are shown in Table 1. The molar compositions, surface area and porosity of TR-TEBOP showed marginal difference as compared to AC-TEBOP, however the increase in yield per batch was more than $30 \%$ (Table 1). Other than shortening the synthesis time from $96 \mathrm{~h}$ (at $160{ }^{\circ} \mathrm{C}$ ) to $2 \mathrm{~h}$ (at $210{ }^{\circ} \mathrm{C}$ ) the effect of replacing $\mathrm{AC}$ by $\mathrm{TR}$ on the physiochemical traits of TR-TEBOP remains unclear. Fig. S5 $\uparrow$ and Table 2 also display impetus information on the results of hydrothermal aging of the SSZ-16 samples (based on their crystallinity factor), which could very well clarify the uncertainty surrounding the advantages of involving TR. The intensity of the XRD peaks (Fig. S5 ${ }^{\dagger}$ ) are intact until an hydrothermal aging temperature of $750{ }^{\circ} \mathrm{C}$ above which it deteriorates for $\mathrm{Cu}-\mathrm{AC}$ DABCO and Cu-AC-TEBOP. Cu-AC-DABCO undergoes complete degradation at $800{ }^{\circ} \mathrm{C}$ and $\mathrm{Cu}-\mathrm{AC}-\mathrm{TEBOP}$ despites retaining AFX phase became highly amorphous. Table 2 compares the percentage of relative crystallinity (calculated from the XRD patterns) of these samples. Only Cu-TR-TEBOP managed to retain the AFX phase throughout the hydrothermal aging process (Fig. S5†). The essence of Fig. S5† and

Table 1 Comparison of physicochemical data of SSZ-16 zeolites before and after copper exchange

\begin{tabular}{|c|c|c|c|c|c|}
\hline \multirow[b]{2}{*}{ Sample name } & \multicolumn{2}{|c|}{$\begin{array}{l}\text { ICP molar } \\
\text { ratio }\end{array}$} & \multirow{2}{*}{$\begin{array}{l}\text { BET surface } \\
\text { area }\left(\mathrm{m}^{2} \mathrm{~g}^{-1}\right)\end{array}$} & \multirow{2}{*}{$\begin{array}{l}\text { Micropore volume } \\
\left(\mathrm{cc} \mathrm{g}^{-1}\right)\end{array}$} & \multirow{2}{*}{$\begin{array}{l}\text { Yield } \\
(\%)\end{array}$} \\
\hline & $\mathrm{Si} / \mathrm{Al}$ & $\mathrm{Cu} / \mathrm{Al}$ & & & \\
\hline AC-DABCO & 3.18 & 0.00 & 621 & 0.23 & 33 \\
\hline AC-TEBOP & 4.63 & 0.00 & 687 & 0.26 & 51 \\
\hline TR-TEBOP & 4.66 & 0.00 & 679 & 0.26 & 82 \\
\hline Cu-AC-DABCO & 3.17 & 0.33 & 627 & 0.23 & \\
\hline Cu-AC-TEBOP & 4.60 & 0.36 & 594 & 0.20 & \\
\hline Cu-TR-TEBOP & 4.77 & 0.33 & 620 & 0.22 & \\
\hline
\end{tabular}


Table 2 Comparison of physicochemical data of the copper ionexchanged samples before and after hydrothermal aging

\begin{tabular}{|c|c|c|c|}
\hline Sample name & $\begin{array}{l}\text { BET surface area } \\
\left(\mathrm{m}^{2} \mathrm{~g}^{-1}\right)\end{array}$ & $\begin{array}{l}\text { Micropore volume } \\
\left(\mathrm{cc} \mathrm{g}^{-1}\right)\end{array}$ & $\begin{array}{l}\text { Crystallinity } \\
(\%)\end{array}$ \\
\hline Cu-AC-DABCO & 627 & 0.23 & 100 \\
\hline Cu-AC-DABCO-700 & 617 & 0.23 & 86 \\
\hline Cu-AC-DABCO-750 & 616 & 0.22 & 75 \\
\hline Cu-AC-DABCO-800 & 4 & 0 & 0 \\
\hline Cu-AC-TEBOP & 594 & 0.20 & 100 \\
\hline Cu-AC-TEBOP-700 & 656 & 0.24 & 88 \\
\hline Cu-AC-TEBOP-750 & 679 & 0.25 & 86 \\
\hline Cu-AC-TEBOP-800 & 127 & 0.04 & 12 \\
\hline Cu-TR-TEBOP & 620 & 0.22 & 100 \\
\hline Cu-TR-TEBOP-700 & 616 & 0.21 & 89 \\
\hline Cu-TR-TEBOP-750 & 579 & 0.19 & 88 \\
\hline Cu-TR-TEBOP-800 & 477 & 0.16 & 69 \\
\hline
\end{tabular}

Table 2 in terms of hydrothermal stability depicted as crystallinity curves is shown in Fig. 1. Plotted as a function of hydrothermal aging temperature, these crystallinity curves support the fact that compared to DABCO, TEBOP produces SSZ-16 zeolite with high hydrothermal stability especially when tubular reactor was employed.

The micropore volumes of the SSZ-16 samples prepared from TEBOP is apparently higher than the one prepared from DABCO (Tables 1 and 2). Crystals of Cu-AC-DABCO were spindled hexagonal while samples from TEBOP show di-hexahedron morphology (Fig. 2). As for the particle size, Cu-AC-DABCO is the largest $(2 \mu \mathrm{m})$ with Cu-TR-TEBOP being larger (with a broad size distribution) than Cu-AC-TEBOP. Though, the influence of increasing hydrothermal aging temperature over the crystallinity of Cu-TR-TEBOP sample series was clearly evident from XRD (crystallinity) data, any changes in their particle size and morphology were not observed from their SEM images (Fig. 3). The ESR spectra of the fresh and aged samples are shown in Fig. $4 \mathrm{a}$ and $\mathrm{b}$ respectively. Only the paramagnetic copper cations $\left(\mathrm{Cu}^{2+}\right)$ are ESR active while $\mathrm{Cu}^{+}$and $\mathrm{Cu}^{0}$ remain anonymous to ESR. The peaks at lower field confirmed the presence of $\mathrm{Cu}^{2+}$

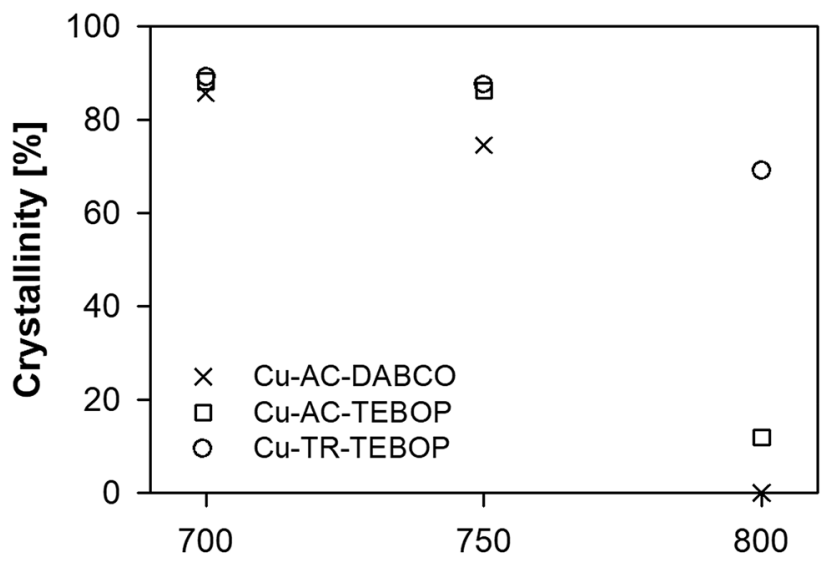

Aging Temperature $\left[{ }^{\circ} \mathrm{C}\right]$

Fig. 1 Comparison of crystallinity curves of the fresh copper-ion exchanged SSZ-16 samples plotted as a function of hydrothermal aging temperature.

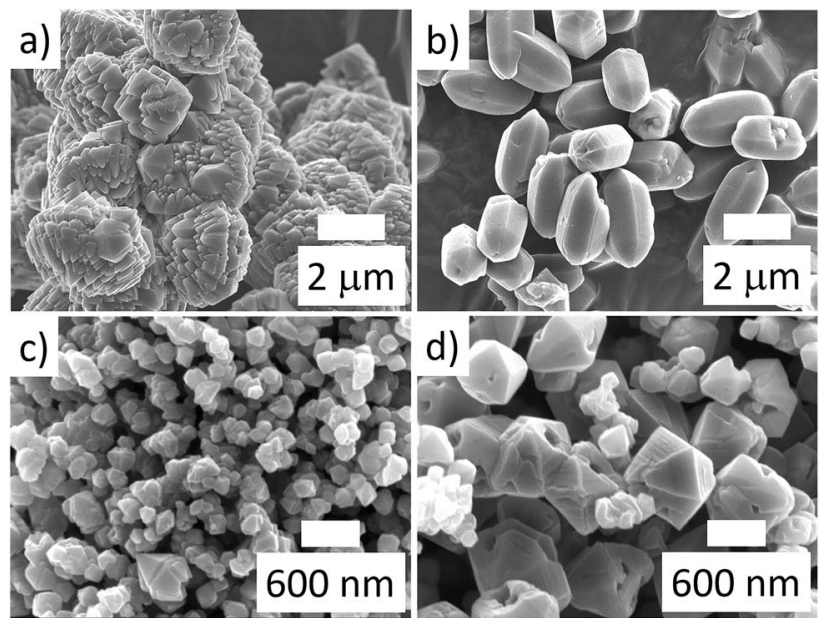

Fig. 2 SEM images of SSZ-16 samples (a) seed; (b) Cu-AC-DABCO; (c) CU-AC-TEBOP; (d) Cu-TR-TEBOP.

species in fresh samples (Fig. 4a). At $700{ }^{\circ} \mathrm{C}$ hydrothermal aging, the signal intensity of Cu-TR-TEBOP decreased, however, it remained almost unchanged when the hydrothermal aging temperature was increased further till $800{ }^{\circ} \mathrm{C}$ (Fig. 4b) and resolving their hyperfine structures at room temperature ESR measurements is unlikely, probably due to the interference from the ionic mobility and dipolar interactions of the $\mathrm{Cu}^{2+}$ species. ${ }^{53,54}$ As such, the ESR results revealed that the hydrothermal aging at varying temperatures did not alter the state of the copper species in Cu-TR-TEBOP sample series, which is of critical importance for their SCR of NOx activity.

The ${ }^{29}$ Si MAS NMR spectrum of all the samples except Cu-ACDABCO shows two peaks at $-116.8 \mathrm{ppm}$ and $-111.0 \mathrm{ppm}$ (Fig. $4 \mathrm{c}$ and $\mathrm{d}$ ) corresponding to $\mathrm{Q}^{4}\left(\mathrm{Si}(\mathrm{OSi})_{4}\right)$ and $\mathrm{Q}^{4}$ $\left(\mathrm{Si}(\mathrm{OAl})(\mathrm{OSi})_{3}\right)$ species respectively. Cu-AC-DABCO exhibited an additional shoulder peak around $-105 \mathrm{ppm}$ that corresponds to $\mathrm{Q}^{4}\left(\mathrm{Si}(\mathrm{OAl})_{2}(\mathrm{OSi})_{2}\right)$ species (Fig. 4c). The intensity of the NMR signals for $\mathrm{Q}^{4}\left(\mathrm{Si}(\mathrm{OAl})(\mathrm{OSi})_{3}\right)$ in Cu-TR-TEBOP sample weakened with increasing the hydrothermal aging temperature from 700 to $800{ }^{\circ} \mathrm{C}$ (Fig. 4d) which might be due to partial structural
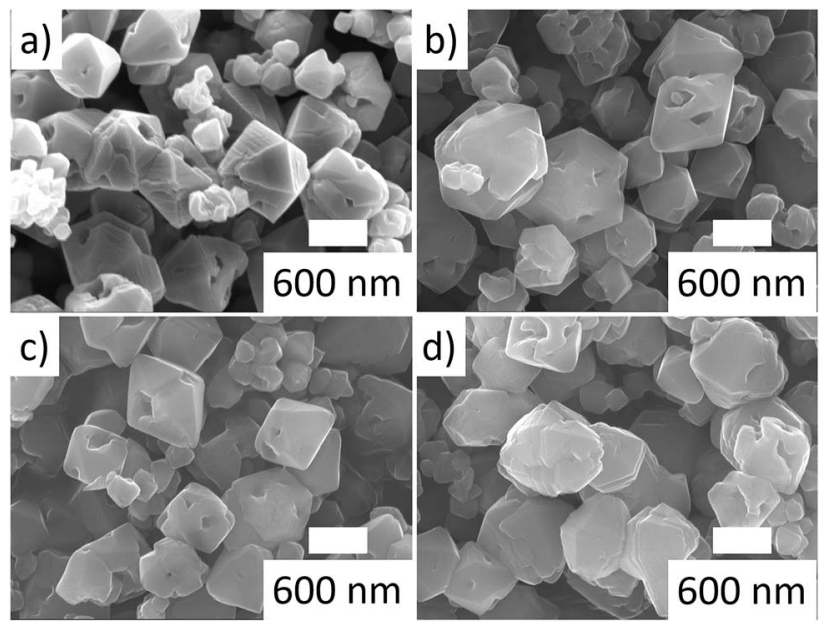

Fig. 3 SEM images of Cu-TR-TEBOP samples (a) Cu-TR-TEBOP; (b) Cu-TR-TEBOP-700; (c) Cu-TR-TEBOP-750; (d) Cu-TR-TEBOP-800. 

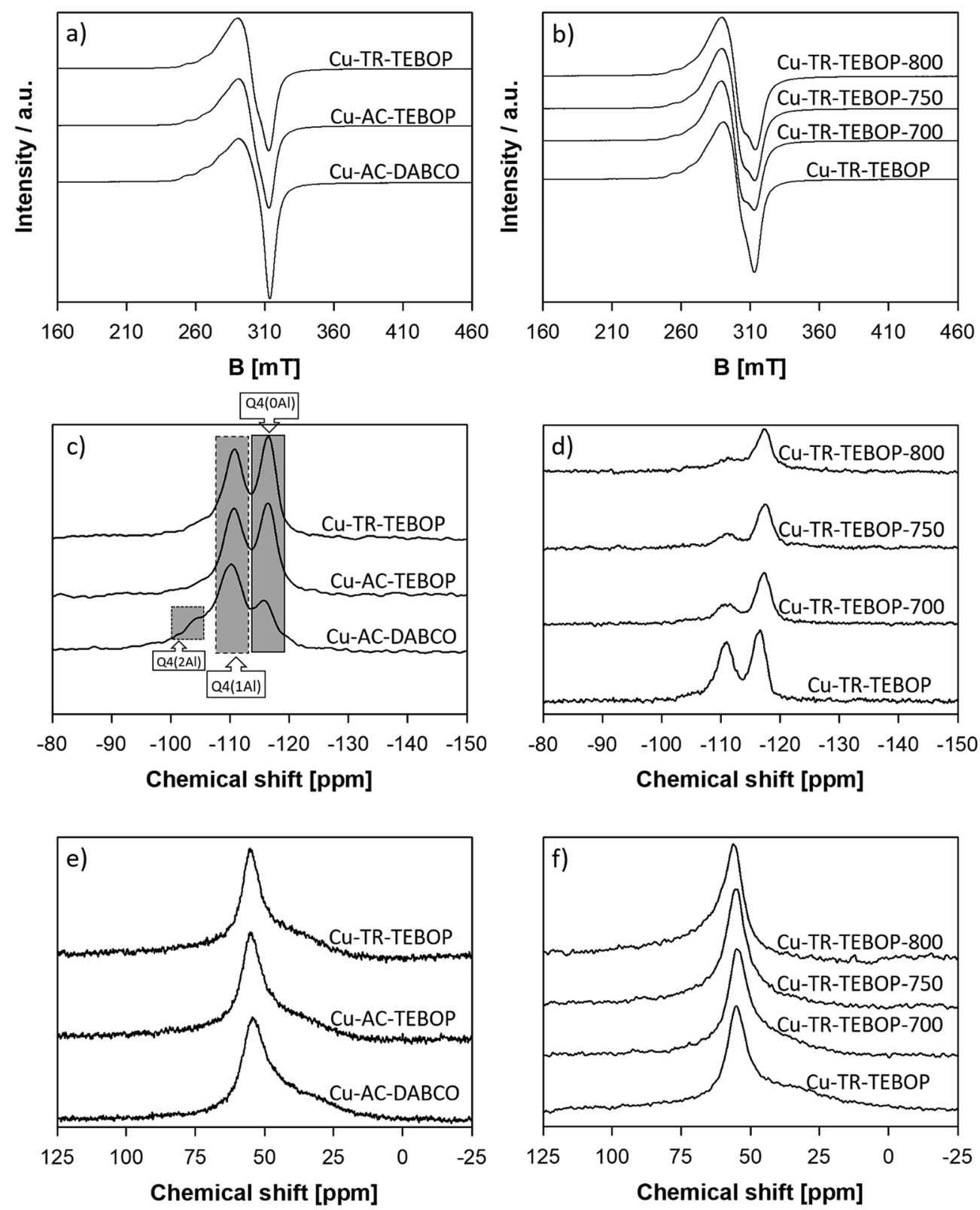

Fig. 4 ESR spectra of SSZ-16 samples (a) fresh and (b) Cu-TR-TEBOP series; ${ }^{29}$ Si solid MAS NMR of (c) fresh and (d) Cu-TR-TEBOP series and ${ }^{27} \mathrm{Al}$ solid MAS NMR of (e) fresh and (f) Cu-TR-TEBOP series.

collapse and dealumination. The ${ }^{27} \mathrm{Al}$ MAS NMR of all the samples exhibited one peak in the range of 54.4 to $56.9 \mathrm{ppm}$ characteristics of tetrahedral coordinated framework aluminum atoms (Fig. 4e and f). Absence of signal near $0 \mathrm{ppm}$ indicates that all the samples are free from octahedral or extra framework aluminum species. Especially, Fig. $4 \mathrm{f}$ confirmed that the aluminum atoms in Cu-TR-TEBOP remained intact with tetrahedral coordination even after undergoing high temperature rigorous hydrothermal aging treatment.

Fig. $5 \mathrm{a}$ and $\mathrm{b}$ compares the performance of the Cu-AC-TEBOP and Cu-TR-TEBOP samples in the SCR of NOx as a function of temperature. Their tendency to reduce NOx over the entire SCR temperature range (i.e. 150 to $600^{\circ} \mathrm{C}$ ) remained practically the same (i.e. 100\%) until the hydrothermal aging temperature of $700{ }^{\circ} \mathrm{C}$. However, the activity of Cu-AC-TEBOP-800 dropped drastically while $\mathrm{Cu}$-TR-TEBOP-800 managed to achieve well above $80 \%$ NOx conversion exposing the fact that how the crystallinity of the latter has been enhanced to withstand rigorous hydrothermal aging conditions.

Though we have previously accounted the role of TRs at higher synthesis temperature as a means to shorten the synthesis time of several zeolites, the high hydrothermal stability and SCR performance of Cu-TR-TEBOP-800 despites having its physio-chemical data comparatively similar (except particle size) to Cu-AC-TEBOP is quite intriguing. In accordance with our previous studies, ${ }^{35,42}$ we conclusively highlight that the degree of healing structural defects under high temperature ultrafast synthesis as a most probable cause for the high hydrothermal stability and therefore SCR activity of Cu-TR-TEBOP. Still it is tedious to evaluate the exact amount of defects, we used hydrothermal aging and SCR 

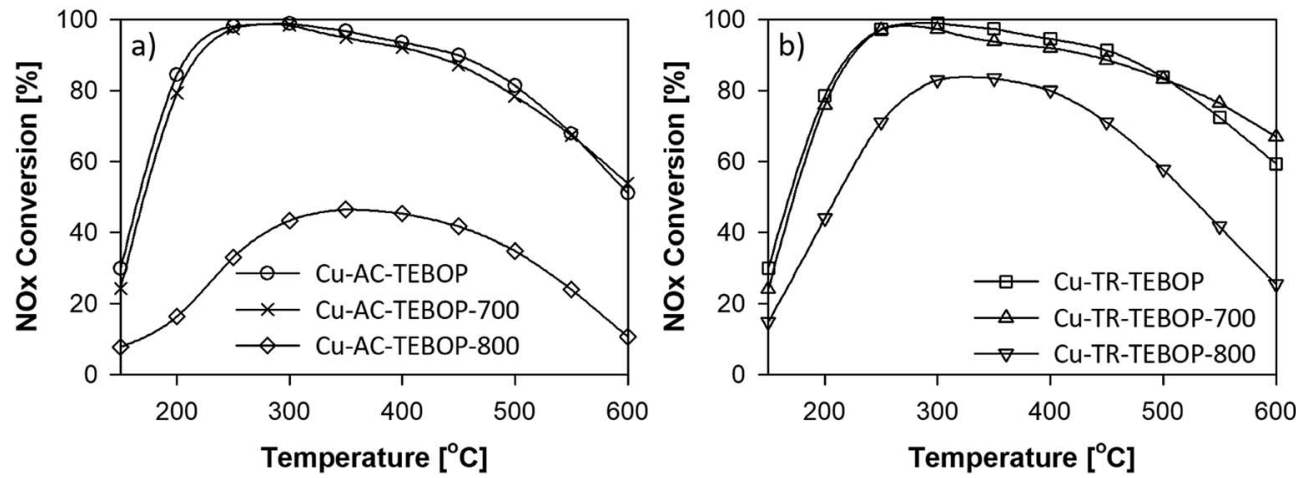

Fig. $5 \mathrm{NH}_{3}$ SCR of NOx performance of (a) Cu-AC-TEBOP series; (b) Cu-TR-TEBOP series.

assessment supported by the SEM images of both fresh and aged $\mathrm{Cu}$-TR-TEBOP samples (Fig. 3a-d) to apparently understand the influence of defects in Cu-AC-TEBOP and the role of high temperature ultrafast synthesis in healing them in Cu-TR-TEBOP.

\section{Conclusion}

The synthesis of SSZ-16 zeolites using TEBOP (a recently reported OSDA for AFX synthesis) has been achieved in just $2 \mathrm{~h}$ for the first time following a novel ultrafast synthesis route involving tubular reactors. The TR combined with high synthesis temperature and seed assistance plays a pivotal role for synthesizing SSZ-16 in $2 \mathrm{~h}$ (instead of 4 days in autoclaves (AC)). After copper exchange and hydrothermal aging at $700{ }^{\circ} \mathrm{C}$, both the Cu-TR-TEBOP and Cu-AC-TEBOP samples exhibited physio-chemical properties and SCR of NOx activity with marginal difference. However, Cu-TR-TEBOP revealed higher hydrothermal stability by retaining its $\mathrm{NH}_{3}$-SCR of NOx activity even after hydrothermal aging at $800{ }^{\circ} \mathrm{C}$. It was found that the particles of Cu-AC-TEBOP are majorly defective but the high temperature synthesis medium in Cu-TR-TEBOP initiates a rapid healing process to reduce the structural defects. Therefore, the high crystallinity, hydrothermal stability and SCR activity of Cu-TR-TEBOP specific to $800{ }^{\circ} \mathrm{C}$ hydrothermal aging is due to structurally healed crystals.

\section{Conflicts of interest}

There are no conflicts to declare.

\section{References}

1 S. E. Lehman and S. C. Larsen, Environ. Sci.: Nano, 2014, 1, 200-213.

2 P. A. Jacobs, M. Dusselier and B. F. Sels, Angew. Chem., Int. Ed., 2014, 53, 8621-8626.

3 E. Khodaverdi, H. A. Soleimani, F. Mohammadpour and F. Hadizadeh, Chem. Biol. Drug Des., 2016, 87, 849-857.

4 T. Stavrakou, J. F. Muller, K. F. Boersma, D. Smedt and R. J. van der A, Geophys. Res. Lett., 2008, 35, 1-5.

5 U. Latza, S. Gerdes and X. Baur, Int. J. Hyg. Environ. Health, 2009, 212, 271-287.
6 P. Schneider and R. J. van der A, J. Geophys. Res., 2012, 117, 117.

7 A. Saiz-Lopez, R. Borge, A. Notario, J. A. Adame, D. de la Paz, X. Querol, B. Artinano, F. J. Gomez-Moreno and C. A. Cuevas, Sci. Rep., 2017, 7, 45956.

8 S. Brandenberger, O. Krocher, A. Tissler and R. Althoff, Catal. Rev., 2008, 50, 492-531.

9 Z. Xie, X. Zhou, H. Wu, L. Chen, H. Zhao, Y. Liu, L. Pan and H. Chen, Sci. Rep., 2016, 6, 30132.

10 S. Vishnu Priya, T. Ohnishi, Y. Shimada, Y. Kubota, T. Masuda, Y. Nakasaka, M. Matsukata, K. Itabashi, T. Okubo, T. Sano, N. Tsunoji, T. Yokoi and M. Ogura, Bull. Chem. Soc. Jpn., 2018, 91, 355-361.

11 M. Iwamoto and H. Hamada, Catal. Today, 1991, 10, 57-71. 12 H. Y. Chen and W. M. H. Sachtler, Catal. Today, 1998, 42, 7383.

13 R. Q. Long and R. T. Yang, J. Am. Chem. Soc., 1999, 121, 55955596.

14 F. Gao, J. H. Kwak, J. Szanyi and C. H. F. Peden, Top. Catal., 2013, 56, 1441-1459.

15 I. Bull, et al., U.S. Pat., 7601662 B2, 2009.

16 I. Bull, et al., U.S. Pat., 7704475 B2, 2010.

17 P. J. Andersen, et al., U.S. Pat., 7998443 B2, 2011.

18 P. J. Andersen, et al., U.S. Pat., 8182777 B2, 2012.

19 P. G. Plakeman, E. M. Burkholder, H. Y. Chen, J. E. Collier, J. M. Fedeyko, H. Jobson and R. R. Rajaram, Catal. Today, 2014, 231, 56-63.

20 D. W. Fickel, E. D'Addio, J. A. Lauterbach and R. F. Lobo, Appl. Catal., B, 2011, 102, 441-448.

21 M. Moliner, C. Franch, E. Palomares, M. Grill and A. Corma, Chem. Commun., 2012, 48, 8264-8266.

22 A. L. Picone, S. J. Warrender, A. M. Z. Slawin, D. M. Dawson, S. E. Ashbrook, P. A. Wright, S. P. Thompson, L. Gaberova, P. L. Llewellyn, B. Moulin, A. Vimont, M. Daturi, M. B. Park, S. K. Sung, N. In-Sik and S. B. Hong, Microporous Mesoporous Mater., 2011, 146, 36-47.

23 D. Xie, L. B. McCusker, C. Baerlocher, S. I. Zones, W. Wan and X. Zou, J. Am. Chem. Soc., 2013, 135, 10519-10524.

24 T. M. Davis, A. T. Liu, C. M. Lew, D. Xie, A. I. Benin, S. Elamori, S. I. Zones and M. W. Deem, Chem. Mater., 2016, 28, 708-711. 
25 J. D. Albarracin-Caballero, I. Khurana, J. R. Di lorio, A. J. Shih, J. E. Schmidt, M. Dusselier, M. E. Davis, A. Yezerets, J. T. Miller, F. H. Ribeiro and R. Gounder, React. Chem. Eng., 2017, 2, 168-179.

26 J. Li, X. Jin, H. Duan, N. Ji, C. Song and Q. Liu, Procedia Eng., 2015, 121, 967-974.

27 P. Hrabanek, A. Zikanova, T. Supinkova, J. Drahokoupil, V. Fila, M. Lhotka, H. Dragounova, F. Laufek, L. Brabec, I. Jirka, B. Bernauer, O. Prokopova, V. Martin-Gil and M. Kocirik, Microporous Mesoporous Mater., 2016, 228, 107115.

28 Q. Li, D. Creaser and J. Sterte, The Synthesis of Small Colloidal Crystals of TPA-silicalite-1 with Short Synthesis Time and High Yields, in Porous Materials in Environmentally Friendly Processes, ed. I. Kiricsi, G. PàlBorbèly, J. B. Nagy and H. G. Karge, Elsevier, Amsterdam, 1999, vol. 125, pp. 133-140.

29 P. Pal, J. K. Das, N. Das and S. Bandyopadhyay, Ultrason. Sonochem., 2013, 20, 314-321.

30 Z. Liu, K. Okabe, C. Anand, Y. Yonezawa, J. Zhu, H. Yamada, A. Endo, Y. Yanaba, T. Yoshikawa, K. Ohara, T. Okubo and T. Wakihara, Proc. Natl. Acad. Sci. U. S. A., 2016, 113, 14267-14271.

31 J. Cejka; R. E. Morris and P. Nachtigall, Zeolites in Catalysis: Properties and Applications, Royal Society of Chemistry, Croydon, London, 2017.

32 Catalysts for Fine Chemical Synthesis, ed. E. G. Derouane and S. M. Roberts, John Wiley \& Sons, London, 2006.

33 U. Schubert and N. Hüsing, Synthesis of Inorganic Materials, John Wiley \& Sons, Weinheim, Germany, 2012.

34 E. Verheyen, L. Joos, K. V. Havenbergh, E. Breynaert, N. Kasian, E. Gobechiya, K. Houthoofd, C. Martineau, M. Hinterstein, F. Taulelle, V. V. Speybroeck, M. Waroquier, S. Bals, G. V. Tendeloo, C. E. A. Kirschhock and J. A. Martens, Nat. Mater., 2012, 11, 1059-1064.

35 Z. Liu, T. Wakihara, D. Nishioka, K. Oshima, T. Takewaki and T. Okubo, Chem. Commun., 2014, 50, 2526-2528.

36 Z. Liu, T. Wakihara, K. Oshima, D. Nishioka, Y. Hotta, S. P. Elangovan, Y. Yanaba, T. Yoshikawa, W. Chaikittisilp, T. Matsuo, T. Takewaki and T. Okubo, Angew. Chem., Int. Ed., 2015, 54, 5683-5687.

37 Z. Liu, N. Nomura, D. Nishioka, Y. Hotta, T. Matsuo, K. Oshima, Y. Yanaba, T. Yoshikawa, K. Ohara, S. Kohara,
T. Takewaki, T. Okubo and T. Wakihara, Chem. Commun., 2015, 51, 12567-12570.

38 Z. Liu, T. Wakihara, N. Nomura, T. Matsuo, C. Anand, S. P. Elangovan, Y. Yanaba, T. Yoshikawa and T. Okubo, Chem. Mater., 2016, 28, 4840-4847.

39 Z. Liu, T. Wakihara, C. Anand, S. H. Keoh, D. Nishioka, Y. Hotta, T. Matsuo, T. Takewaki and T. Okubo, Microporous Mesoporous Mater., 2016, 223, 140-144.

40 J. Zhu, Z. Liu, A. Endo, Y. Yanaba, T. Yoshikawa, T. Wakihara and T. Okubo, CrystEngComm, 2017, 19, 632-640.

41 J. Zhu, Z. Liu, K. Iyoki, C. Anand, K. Yoshida, Y. Sasaki, S. Sukenaga, M. Ando, H. Shibata, T. Okubo and T. Wakihara, Chem. Commun., 2017, 53, 6796-6799.

42 C. Peng, Z. Liu, A. Horimoto, C. Anand, H. Yamada, K. Ohara, S. Sukenaga, M. Ando, H. Shibata, T. Takewaki, R. R. Mukti, T. Okubo and T. Wakihara, Microporous Mesoporous Mater., 2018, 255, 192-199.

43 N. Nakazawa, S. Inagaki and Y. Kuboto, Adv. Porous Mater., 2016, 4, 219-229.

44 N. Martin, C. Paris, P. N. R. Vennestrom, J. R. Thogersen, M. Moliner and A. Corma, Appl. Catal., B, 2017, 217, 125-136. 45 S. I. Zones, U.S. Pat., 4508837, 1985.

46 S. I. Zones and R. A. V. Nordstrand, Zeolites, 1988, 8, 409.

47 S. I. Zones, U.S. Pat., 5194235, 1993.

48 R. F. Lobo, S. I. Zones and R. C. Medrud, Chem. Mater., 1996, 8, 2409.

49 A. Jackowski, S. I. Zones, S.-J. Hwang and A. W. Burton, J. Am. Chem. Soc., 2009, 131, 1092.

50 R. H. Archer, S. I. Zones and M. E. Davis, Microporous Mesoporous Mater., 2010, 130, 255.

51 H. Yamada, T. Iida, Z. Liu, Y. Naraki, K. Ohara, S. Kohara, T. Okubo and T. Wakihara, Cryst. Growth Des., 2016, 16, 3389-3394.

52 S.-H. Lee, C.-H. Shin, G. J. Choi, T.-J. Park, I.-S. Nam, B. Han and S. B. Hong, Microporous Mesoporous Mater., 2003, 60, 237-247.

53 F. Gao, E. D. Walter, E. M. Karp, J. Luo, R. G. Tonkyn, J. H. Kwak, J. Szanyi and C. H. F. Peden, J. Catal., 2013, 300, 20-29.

54 A. Kharchenko, V. Zholobenko, A. Vicente, C. Fernandez, H. Vezin, V. De Waele and S. Mintova, Phys. Chem. Chem. Phys., 2018, 20, 2880-2889. 